\title{
Researching teachers, support to teachers—and teaching
}

\author{
Jeppe Skott ${ }^{1}$
}

Published online: 26 June 2018

(c) Springer Nature B.V. 2018

Current recommendations for a reform of school mathematics do not make it any easier to teach. On the contrary, they require teachers to base instruction on continuous interpretations of their students' learning and current understandings; to involve students in mathematical practices of, for instance, problem solving and reasoning; and on the spot to capitalise on the individual and communal learning potentials of the somewhat unpredictable outcomes of such involvement. Further there is much emphasis on equity issues, not least in relation to students with other mother tongues than the language of instruction, and on the requirement that teachers capitalise on the potentials of technology for student learning. The complexities involved in this, accentuated by the planned unpredictability involved when teachers have to base instruction on students' contributions to classroom interaction, have been researched in studies of teachers (e.g. of their knowledge and beliefs), of support to teachers (e.g. teacher education and development initiatives), and of teaching, that is, teachers' actions during lessons and to a lesser extent their actions before and after lessons.

The studies presented in this issue of JMTE align with the first two of these research categories. In the first article, Ren and Smith present a quantitative study of the relationship among teacher characteristics (e.g. experience and certification), teacher knowledge, and contextual factors on the one hand and teachers' affective relationships with mathematics (their beliefs and attitudes) on the other. Teachers' beliefs and attitudes are often considered significant determiners of instructional quality and classroom practice, and an impressive amount of research has tried to document that they do indeed play a significant role. Ren and Smith build on this prior research and take the significance of teachers' beliefs and attitudes as a premise for their study of elementary teachers from Nebraska, USA. The question for Ren and Smith, then, concerns how affective issues are linked to other characteristics of teachers and to aspects of the context for their professional lives as documented in a survey.

Among the findings in the study by Ren and Smith, it is noticeable that (1) reformoriented beliefs and positive attitudes towards mathematics are positively correlated with teachers' mathematical knowledge for teaching; (2) that student centred beliefs are positively correlated with teachers perceived support from their colleagues and the school leadership; and (3) that contextual factors (urban or rural school, proportion of ELL students, communication with families) are unrelated to teachers' beliefs and attitudes.

Jeppe Skott

jeppe.skott@lnu.se

1 Växjö, Sweden 
In their discussion of the study, Ren and Smith build on their own findings as well as on other research in the field. A main suggestion is that teacher education and development programmes should not focus on knowledge and affect in mutual isolation and that change in beliefs and attitudes may best be supported if connected to the development of teachers' mathematical knowledge for teaching. Another suggestion for future research is to develop a better understanding of the role of "context". To some extent, these suggestions are in line with developments in other research on affect that do not see beliefs and attitudes as independent determiners of teacher action, but as part of a dynamic affect system that relate both to other mental constructs and to the contexts in which teachers work.

In their article, Estapa and her colleagues look at novel ways to support prospective teachers (PSTs) in developing their capacity for professional noticing. Professional noticing may be described as observing significant aspects of classroom practice, making contextually relevant interpretations that draw on broader understandings of mathematics and its teaching and learning, and using the interpretations to inform subsequent classroom action. Considering the planned unpredictability of classroom practices (cf. the introduction to this editorial), it is of obvious importance what teachers notice and how they react to or build on whatever they do notice when interacting with their students.

As noted by Estapa et al., professional noticing is not an easy discipline to master. In their project, they use a mixed-methods design to investigate (1) who and what PSTs notice when asked to select and write about episodes from a video of an interaction in a grade 4 classroom; (2) what reasons the PSTs provide for their selection when writing about it; and (3) how they use the selected episode for an animation of practice that they make themselves. It is an interesting finding that while the majority of the research participants focus their attention on the students in their written accounts, most of them pay more attention to the teacher in their subsequent animation, that is, in a situation in which they are to actively present the episode they had selected. Also, the PSTs to a greater extent noticed specific aspects of the episode in their animations in comparison with more general accounts that dominate their written work. Finally, it is a characteristic of the written accounts that most of them are descriptive and some are evaluative and interpretive, while just a couple are reflective.

Although Estapa et al.'s study does not primarily address the question of the differences between PSTs written accounts and animations, their findings do suggest that the two media provide different opportunities to notice. Also, the study invites a reflection on and further investigation of whether and why approximations of practice, for instance with the use of animations, provide (prospective) teachers with opportunities to reflect on what they notice and take noticing beyond the mere description of practice that sometimes dominates their analyses of representations of practice in the form of video.

In the last article in this issue, Fuentes and Ma discuss a very different way of supporting teachers in aligning with reform efforts. They present a framework, TLO-Math, for designing and evaluating the educative potential of curricular materials, that is, the degree to which the materials provide opportunities for teacher learning, rather than merely support for students to develop their mathematical proficiency. This requires that teacher guides include explanations both of how the materials may be used and the rationale behind the choices made by the authors of the materials with regard to contents, examples, and suggested pedagogical moves.

Fuentes and Ma's framework for educative features of curricular materials has seven dimensions. The dimensions, which are based on a review of the relevant literature in the field, are all described as different aspects of teacher knowledge. The dimensions are teachers' knowledge of (1) content for teaching, (2) student thinking in mathematics, (3) 
disciplinary discourse in mathematics, (4) assessment, (5) differentiated instruction, (6) the use of technology, and (7) mathematical community. These dimensions position the framework squarely within the reform as outlined previously. To illustrate the use of TLO-Math, Fuentes and Ma analyse two sets of curricular materials for elementary school. Based on the analyses, they argue that the two sets of materials provide different opportunities for teacher learning and that the TLO-Math framework may help teachers and teacher educators understand the educative features of curricular materials.

The three articles in this issue of JMTE in very different ways address questions related to what it takes for teachers to be able to meet the professional challenges inherent in the reform. The article by Ren and Smith is on teachers. It describes how affective issuesoften considered a necessary condition for teachers to comply with the recommendations of the reform-are linked to other characteristics of the teachers themselves and of the contexts in which they work. The two other articles, by Estapa et al. and by Fuentes and Ma, are concerned with how prospective and practising teachers' may be supported in developing teaching strategies considered compatible with the reform.

Notwithstanding the obvious potentials of both these lines of research, one may also point to some limitations. Ren and Smith say that while they did ask questions about "context" and about teachers' communication with the students' families, a more elaborate understanding of and approach to researching "context" is needed in future studies. In their important study of teacher noticing, Estapa et al. find that who, what, and possibly how prospective teachers notice depend on the medium they use and on whether PSTs are asked to decompose or approximate practice. The differences are critical, but based on relatively minor changes in the "context" of PSTs professional learning. One may wonder how the content and character of teacher noticing may be influenced by the complexities of teaching and very different contexts that emerge in ordinary mathematics classrooms. And Fuentes and Ma suggest that their development of the TLO-Math framework is but a first step in the study of the educative potential of curricular materials. They also say that one possible next step is to study how practising teachers capitalise on and learn from the potentials of educative materials.

The teacher is of obvious and undisputed significance for the practices that unfold in mathematics classrooms. Consequently support to teachers in teacher education programmes or by use of curricular materials is of paramount importance. The articles in this issue of JMTE present important studies that in different ways seek to support teachers in taking on the difficult professional obligations inherent in the reform or to provide understandings that may form the basis for developing such support. There is every reason to take the findings of the three studies seriously. However, the limitations pointed to above suggest that we need to study not only teachers and support to their professional learning. Based on such studies, we need also to focus on teaching in the complex "contexts" of the everyday classroom. 